InterSedes, Revista electrónica de las sedes regionales de la Universidad de Costa Rica, ISSN 2215-2458, Vol XXI, Número 43, Enero - Julio, 2020.

10.15517/isucr.v21i43.41973 | intersedes.ucr.ac.cr | intersedes@ucr.ac.cr

\title{
LA LEYENDA GUANACASTECA "LA MONA": ESTRATEGIA DIDÁCTICA PARA EL DESARROLLO DEL PENSAMIENTO CRÍTICO Y LA COMPETENCIA CULTURAL DESDE EL AULA UNIVERSITARIA
}

\section{"LA MONA" GUANACASTECAN LEGEND: TEACHING STRATEGY TO DEVELOP CRITICAL THINKING AND CULTURE COMPETENCE IN THE UNIVERSITY CLASSROOM}

\author{
Karol Cubero Vásquez ${ }^{1}$
}

Lucía Villanueva Monge ${ }^{2}$

\begin{tabular}{|l|l} 
Recibido: 29.11 .18 & Aprobado: 30.04 .20
\end{tabular}

DOI: $10.15517 /$ isucr.v21i43.41973

\section{Resumen:}

Los tiempos dinámicos en que vivimos nos obligan, constantemente, a adoptar nuevas maneras de emprender acciones. Nuestra tarea formativa no es la excepción. Esta dinámica social nos presenta un reto permanente como docentes en la búsqueda de nuevas formas de aprender en el aula universitaria. Los estudiantes demandan cambios continuos en mediación pedagógica que les permita ser partícipes de un aprendizaje duradero y disfrutable. Con la utilización de las leyendas costarricenses y más específicamente, con la leyenda guanacasteca de "La Mona" en el aula universitaria, se promueve un aprendizaje entretenido y cautivante por el relato mismo que caracteriza al género literario de las leyendas. Este hecho introduce y motiva a los educandos a experimentar un proceso que estimula su capacidad crítica, su creatividad, su expresión oral y escrita, al mismo tiempo que incentiva su acervo cultural, valorando e identificándose con sus propias raíces. Con el desarrollo de actividades didácticas basadas en leyendas costarricenses como la leyenda guanacasteca de "La Mona" aquí propuestas, se logra concretar una premisa primordial: la necesidad latente de formar ciudadanos críticos, competitivos, solidarios, tolerantes, empáticos, amantes de su cultura, resultando un individuo integral y responsable de preservar su propia cultura.

Palabras clave: Leyenda; identidad cultural; pensamiento crítico; aprendizaje significativo.

\footnotetext{
Abstract:

${ }^{1}$ Profesora en la Universidad Nacional, Liberia, Guanacaste, Costa Rica y la Universidad de Costa Rica, Sede Guanacaste, Liberia, Guanacaste, Costa Rica. Email: kacubero@gmail.com

${ }^{2}$ Profesora en la Universidad Nacional, Liberia, Guanacaste, Costa Rica y la Universidad de Costa Rica, Sede Guanacaste, Liberia, Guanacaste, Costa Rica. Email: mongeluc@gmail.com
} 
The present times in which we live push us to constantly adopt new ways of taking actions, and our teaching approach is not the exception. These constant changes challenge educators to innovate learning approaches in the university classroom. Students are also demanding a learning process that enables them to participate in a long-lasting and enjoyable learning experience. For this reason, this article proposes the use of one Costa Rican legend: "La Mona" as a teaching resource to mediate a significant learning experience since this legend captivates by the story itself and motivates students to experience a process that stimulates their critical thinking, creativity, oral and written expression, at the same time that reinforces cultural heritage, values and identity. When using learning activities based on "La Mona" legend, one fundamental idea comes clear: the need to educate critical, competitive tolerant and integral citizens who can be responsible of preserving their own native culture.

Keywords: Legend; cultural identity; critical thinking; significant learning

\section{Introducción}

Las nuevas formas de aprender nos plantean un reto importante en la labor docente. Los estudiantes requieren de constantes cambios en el abordaje y mediación pedagógica que les permita ser partícipes de un aprendizaje duradero y disfrutable. En tal sentido, se reconocen los esfuerzos que realizamos muchos académicos por variar y nutrir la mediación en el salón de clase. Para un buen aprendizaje, docentes y aprehendientes plantean sus intereses y definen sus estrategias para acercarse al objeto del conocimiento. Este entendimiento entre ambas partes, promueve claridad de objetivos, esfuerzos direccionados hacia el aprendizaje integral, a la vez que abre espacios para promover un aprendizaje significativo. Esta propuesta, nace de la necesidad de promover un proceso de aprendizaje que involucre el pensamiento crítico en el cual todos sus componentes, participantes del proceso, indaguen, cuestionen y establezcan sus propias conclusiones sobre diferentes temáticas planteadas. Este proceso se torna, entonces, en una dinámica en la que todas sus partes se involucran activamente, más allá del tener que hacerlo, sino más bien porque les causa curiosidad, les es intrigante, o les cautiva de alguna forma el proceso mismo y es así que se hace de éste uno rico, activo y muy necesario.

Precisamente, esto es lo que se establece en esta propuesta al utilizar las leyendas costarricenses y más específicamente la leyenda guanacasteca de "La Mona" en el aula universitaria. La leyenda "La Mona" se promueve como la ignición o chispa de inicio del proceso de aprendizaje de los estudiantes, quienes, motivados por lo intrigante del relato, van descubriendo en el mismo, aspectos importantes de su propia cultura que los hace sentirse identificados lo que les cautiva aún más. Luego, se prosigue hacia el desarrollo de actividades didácticas que promueven el pensamiento 
crítico mediante interrogantes sobre el cómo, el porqué y el para qué de las cosas u hechos. Simultáneamente, los aprehendientes se reconectan, sienten y se interesan por su propia cultura. Este es uno de los muchos efectos que busca esta propuesta porque, ante todo, existe una premisa importante: la necesidad latente de formar ciudadanos competitivos, solidarios, tolerantes, empáticos amantes de sus raíces y conscientes del gran regalo y legado cultural compartido entre los habitantes de una región/nación el cual se debe cuidar, atesorar, preservar y nutrir. En este sentido, los docentes de este nuevo siglo debemos de comprometernos con nuevos roles que promuevan situaciones de aprendizaje para desarrollar competencias integrales de participación, de identificación cultural, desde el cuestionamiento de hechos. Todo lo anterior, despertando sentimientos, emociones y así, entretenimiento en general que depara el uso didáctico de las leyendas costarricenses en las aulas universitarias.

\section{Referentes Conceptuales}

\section{Cultura e Identidad cultural}

El termino cultura ha sido sujeto de diversas definiciones y perspectivas estas sostienen que cultura es lo que sazona la vida otorgando sentido a la cotidianidad del ser humano. En este aprendizaje y vivencia en comunidad se comparten tradiciones, visión de mundo, costumbres, celebraciones, conocimiento, creencias, moral, prácticas y comportamientos. La cultura como órgano vivo, se nutre de esos patrones heredados, tanto por influencias exteriores como interiores y las mismas son adoptadas o implementadas a nivel de grupo. Según Geertz (1989), La concepción de la cultura desde el punto de vista de mecanismos de control comienza con:

El supuesto de que el pensamiento humano es fundamentalmente social y público. El pensar no consiste en "sucesos que ocurren en la cabeza" (aunque sucesos en la cabeza y en otras partes son necesarios para que sea posible pensar) sino en un tráfico de lo que G.H. Mead y otros llamaron símbolos significativos -en su mayor parte palabras, pero también gestos, ademanes, dibujos, sonidos musicales, artificios mecánicos, como relojes $\mathrm{u}$ objetos naturales como joyas- cualquier cosa, en verdad, que esté desembarazada de su mera actualidad y sea usada para imponer significación a la experiencia. En el caso de cualquier individuo particular esos símbolos ya le están dados en gran medida. Ya los encuentran corrientemente en la comunidad en que nació y esos símbolos continúan 
existiendo, con algunos agregados, sustracciones y alteraciones parciales a las que él puede haber contribuido o no, después de su muerte. (III. párra. $5)$.

Diferentes autores concuerdan que el término cultura implica una telaraña de significados que nosotros, como miembros de una sociedad, tejemos e interactuamos, interpretando y dictando pautas de significados sobre comportamientos y prácticas compartidas. Efectivamente, nuestras prácticas y comportamientos hacen que nos sintamos cómodos, identificados y pertenecientes a una "nuestra" cotidianidad en sociedad.

Geertz expone que el ser humano da significación a su propia existencia al compartir un sistema de símbolos aprendidos y entendidos en la dinámica de interacción reciproca con el mundo y a su vez en relación consigo mismos. Este sistema de símbolos del que nos hablan este y otros autores, constituye la fuente de información que da forma, visión, sentido, dirección y hasta color a la cotidianidad en la que nos desenvolvemos continuamente en comunidad. Esta noción se hace más visible y perceptible al sentir la comodidad de encontrarnos e interactuar en nuestros grupos sociales. Esta interacción segura y amena brinda bienestar y confianza al individuo. Desde esta interacción placentera nos reforzamos y reafirmamos como habitantes partidarios de una cultura en particular.

Precisamente, con esta socialización nos es posible crear y preservar la cultura. Sin la interacción de los miembros de una comunidad no es posible transferir cultura. Las interrelaciones fomentan, preservan y difunden la identidad cultural de un pueblo. Es con la identidad cultural que se da un sentido de pertenencia a un grupo social con el cual se comparten rasgos culturales como costumbres, valores y creencias.

En este sentido, la identidad cultural de un pueblo viene definida históricamente a través de sistemas de valores y creencias. El patrimonio cultural es la herencia recibida del pasado y el depósito de la memoria. El reconocimiento, valoración y conservación del patrimonio cultural se orienta al mantenimiento de nuestra identidad histórica como comunidad humana. (González, 2015).

Como parte del patrimonio de cada cultura encontramos la historia. Este componente ineludible es el que marca la identidad, la que la mantiene a pesar del paso del tiempo, de los cambios y de la globalización. La identidad de un pueblo se lleva en el alma, en el corazón y adquiere valor desde la colectividad. Por tanto, se debe custodiar y trasmitir en mensajes 
significativos desde diversas y creativas formas. La identidad cultural sólo es posible y puede manifestarse a partir del patrimonio o legado cultural, protegido por antepasados y del cual se despliega una responsabilidad de compartirlo, analizarlo y preservarlo. Entonces, la identidad cultural se recrea y refleja desde la individualidad y en cohesión grupal.

Por tanto debemos reflexionar y buscar los medios para reafirmar nuestra cultura. Es primordial lograr este cometido ante los medios de la comunicación masiva y replantearnos posturas adecuadas para el bienestar del hombre, para vivir en armonía entre sí y con el entorno urbano o rural; Debemos emprender un camino de decisiones positivas en comunidad a pesar de nuestras diferencias ideológicas. Se requiere un cambio inmediato. Cada país debe adoptar políticas económicas y culturales que tiendan a mantener esta identidad arraigada en su historia. (Díaz, 2009).

En la búsqueda de esas nuevas formas se destacan las leyendas. Las leyendas como manifestación cultural, expresan con mayor intensidad, un sentido de identidad representativa y común de la vida cotidiana. Dentro de este patrimonio cultural inmaterial, concepto registrado bajo la UNESCO como todas aquellas tradiciones o expresiones vivas heredadas de los antepasados y transmitidas a nuestros descendientes. Dentro de este apartado se encuentran las tradiciones orales, artes del espectáculo, rituales, actos festivos, entre otros, siendo las leyendas elementos vitales de las tradiciones orales. De esta manera, la UNESCO establece al patrimonio cultural intangible como el motor que mueve el sentimiento de identidad cultural de los individuos hacia su sociedad, fortaleciendo este arraigo y sirviendo éste de puente entre el pasado y el futuro.

Así es que las leyendas, consideradas patrimonio cultural inmaterial de la humanidad, pueden y deben ser un instrumento de uso pedagógico para afianzar este acervo de conocimientos culturales que se comparten de boca en boca y que al mismo tiempo, se difunden más allá de las fronteras de los países. Esto, da como resultado, leyendas similares esparcidas por toda la América Latina con claras coincidencias y variaciones que se han ido adaptando de acuerdo al propio entorno. Es una responsabilidad, que desde el sistema educativo, se promueva la riqueza cultural, en este caso las tradiciones orales como las leyendas, para que a través de ellas, sus tradiciones sean reconocidas y transmitidas para ser consideradas como patrimonio cultural por los mismos actores de la sociedad en cuestión. Solo así, se mantendrían vivas, presentes; de lo contrario, no pueden formar parte del patrimonio cultural intangible de los pueblos. 
El aprendizaje integrado

De la torre (2005), describe este tipo de aprendizaje como un proceso mediante el cual se promueven espacios académicos que permiten construir nuevos significados a partir de cosas cotidianas, paralelo al desarrollo de estructuras y habilidades cognitivas que facilitan modificar actitudes, valores y estilos de vida. Este hecho se logra mediante estímulos multi - sensoriales que implican todos los sentidos hacia un claro impulso para pensar, sentir y actuar. Lograr estimular los sentidos, como lo plantea el autor, requiere diferentes estrategias de enseñanza, recursos y nuevos planteamientos. Mediante el uso de material de corte cultural, se genera un abordaje interactivo y grato puesto que fomentamos e integramos en el proceso de diferentes competencias y habilidades que son estímulo para el aprendizaje. De la Torre, expone la importancia de ampliar el campo de estímulos y situaciones, dando lugar a estrategias visuales, de simulación, de imaginación, en alianza con procesos cognitivos y críticos. Es desde estas prácticas abiertas, interactivas y entendidas que el educando encuentra oportunidades para un verdadero aprendizaje significativo, relevante y constructivo.

Estimular este tipo de experiencias académicas es posible desde el análisis de leyendas costarricenses. El compartir o socializar una leyenda en el aula universitaria, permite al educando, no solo sentirse, de alguna manera, identificado con el relato, sino que además, lo faculta para vivir y transportarse desde su imaginación al la historia contada, echando mano a un cúmulo de sentimientos y de emociones que despiertan la misma leyenda y que, a su vez, son un vehículo para la obtención y consolidación del conocimiento pero de manera entretenida. Todo lo anterior, apelando también al pensamiento crítico como base del aprendizaje integrado.

El desarrollo del pensamiento crítico

El pensamiento crítico, hace referencia a un proceso activo, reflexivo, consciente y transcendental. Es un pensamiento que cuestiona, indaga, formula preguntas y busca respuestas. Ennis (2011), define que el pensamiento crítico es primeramente un proceso activo que implica pensar reflexivamente, tomar decisiones y actuar resolviendo problemas. El pensamiento crítico es un pensamiento reflexivo, analiza lo razonado desde una discusión individual y grupal.

De acuerdo con la cita anterior, este proceso fomenta el aprender a interpretar, analizar, sintetizar, evaluar y aplicar la información, con el fin de comunicar, compartir y desarrollar la 
habilidad de procesar y crear nuevo conocimiento y saberes, por lo tanto, el pensamiento crítico es productivo, positivo, emotivo y racional. Para promover el pensamiento crítico, el docente debe facilitar y promover actividades medulares que reten a los estudiantes a pensar y a reflexionar. Esto se obtiene cuando se propicia un ambiente de discusión grupal en el que se respire respeto, cooperación, interacción y negociación para asegurar esos nuevos planteamientos o conocimiento.

La didáctica de pensamiento crítico implica un aprendizaje activo y significativo donde se construye significado por medio de la interacción y el diálogo para desarrollar la curiosidad, el cuestionamiento, la reflexión y el aprovechamiento de conocimientos con el fin de tomar decisiones y ofrecer soluciones. (Paul, 2001). El desarrollo del pensamiento crítico es perfectamente cultivable si se ofrecen las oportunidades académicas (entorno propicio, estrategias y actividades colaborativas y motivacionales) hacia una mediación de aprendizaje efectivo y satisfactorio, tanto dentro del salón de clases como fuera de él.

Dentro del proceso de enseñanza- aprendizaje, el conocimiento y reconocimiento de la cultura toma un rol vital ya que es en ésta donde los individuos aprenden a convivir con los demás, aprenden modales, costumbres y sobre todo, aprenden a socializar. Es importante que los docentes lleven a cabo un constante análisis y una reflexión crítica, sobre materiales de orden cultural que permita la preservación y difusión de la misma. El uso de la literatura en la enseñanza, promueve en los estudiantes la capacidad de predicción, el cuestionamiento, la organización de ideas y la emisión de juicios de valor, entre otros múltiples beneficios.

Actividades para elevar el pensamiento crítico

- Cuestionar: preguntas generadoras y esenciales

- Estudio de casos

- Aprendizaje basado en problemas

- Debate

- Dramatización

— Juego de roles

- Crucigramas 
Las leyendas como recurso didáctico

Según Zeledón (2004), la leyenda viene a representar el folklore narrativo popular y la misma cuenta situaciones fantásticas, irreales, basadas en hechos cotidianos o históricos que ilustran la vida de una sociedad específica desde la perspectiva religiosa, económica o social. Es entonces, que las leyendas nos narran hechos concernientes a seres sobrenaturales, mitológicos, $\mathrm{O}$ bien, de la historia patria, entre muchos otros y que, tradicionalmente, se transmitían de manera oral de generación en generación.

Característica importante de la leyenda es su valor moral; es decir dar lección de vida sobre lo que se debe o no se debe de realizar a través de las historias de miedo, algunas, o de terror otras, que le pasaban a sus personajes. Hoy en día, reconocemos en las leyendas un reflejo de las sociedades que las crean. Así es que las leyendas costarricenses vienen a representar la idiosincrasia del "Tico" y como ejemplos de leyendas ticas contamos en especial, con las leyendas de muertos, aparecidos y milagros de personajes reales o no que la gente inventó para dejar una enseñanza o exagerar una realidad y ser contada o leída por todos, desde los más pequeños, jóvenes y adultos en general. Leyenda en latín significa "lo que debe ser leído" y está relacionada también con una narración escrita que debe ser leída en voz alta y en público. Al respecto, Legorburu (1979), citado por Reyes (2011), explica que la leyenda es un género literario y se ubica dentro del subgénero de la literatura poética o creadora ya que usa tres aspectos importantes para la construcción del texto que son: la narración, la descripción y el diálogo. Lo anterior, con la intervención de elementos como personajes y acciones que giran sobre algún conflicto que se trata de solucionar, las mismas están relacionadas con una persona o grupo, un lugar o acontecimiento, que se combina con episodios imaginativos. Las leyendas versan sobre infinidad de temas como: santos, fantasmas, monstruos, seres sobrenaturales o con poderes fuera de lo normal, siendo las mismas profanas, religiosas o mixtas y de corte popular. La literatura poética es una especial manifestación de una depurada sensibilidad artística con el predominio imaginativo. Entonces las leyendas comparten esta clasificación junto con la lírica, la épica, la novela y el mito, entre otros. Las leyendas se diferencian del mito en que la primera narra acontecimientos después de la creación.

Reyes (2011), menciona que en las leyendas se presentan claramente tres partes: introducción, desarrollo y desenlace, teniendo como base el tiempo y el lugar donde ocurre lo 
relatado y que al ser populares, reafirman la cultura de los pueblos, promoviendo sus valores con mensaje de moraleja pero ésta, a diferencia de la fábula, está más implícita.

Entonces, por las características ya expuestas, las leyendas representan un material didáctico valioso para promover aspectos importantes como los que se mencionan a continuación.

\section{Propuesta didáctica}

El uso de las leyendas costarricenses como recurso didáctico

Al ser las leyendas contadas o leídas, refuerzan la identidad de los pueblos porque promueven valores, costumbres, historia y cultura general. Al ser leídas o contadas, se practica, además de la lectura, la oratoria al expresar ideas para discutir y persuadir. Es así como la utilización de este tipo de literatura en la enseñanza, promueve en los estudiantes la capacidad de predicción, de cuestionarse, organizar ideas y emitir juicios de valor en relación con lo contado. Al conectar a los estudiantes con la historia relatada, los mismos harán relaciones basadas en sus experiencias y conocimientos. De esta manera, el texto proveerá un punto de partida y un contexto muy rico para desarrollar una variedad de actividades relacionadas con la enseñanza, involucrando a los estudiantes creativa y dinámicamente.

Bock en su artículo "Developing materials for the study of literature" (1994) expone los principios en el estudio de la literatura de la siguiente manera:

1. Activa el conocimiento existente.

2. Motiva la predicción

3. Acerca al contexto cultural, histórico y social del texto.

4. Introduce nuevo vocabulario

5. Interacción constante y significativa entre el lector y el texto.

La utilización de la literatura focaliza, como punto primordial, el desarrollo de las competencias lingüistas considerando al lenguaje en si como el objetivo principal. De esta manera, los estudiantes mejoran el lenguaje oral y amplía su vocabulario, en general su competencia comunicativa. Al escuchar el relato, es indudable que la literatura genera creatividad e impulsa a la imaginación con sus relatos fantásticos, impulsado por su carácter impresionista. 
Igualmente, con las leyendas se amplía la perspectiva del espectador con la narración de acontecimientos, costumbres, valores y creencias de la Costa Rica de antaño, que en muchos casos, no han perdido su vigencia. Esto permite el conocimiento de la propia cultura, nos deja reconocer nuestra identidad cultural para valorarla y reflexionar de dónde venimos y hacia donde vamos. Es un medio para conocer las propias emociones y sentimientos. Es así como también con las leyendas se integran aspectos gramaticales, sociolingüísticos, discursivos y estratégicos que convergen con otras prácticas como la interacción entre los estudiantes, mayor énfasis a la producción oral, a la vez que provee situaciones de aprendizaje reales y significativas al contextualizar el aprendizaje. Los estudiantes aprenden por descubrimiento, interrelacionándose con el contenido y el tema en estudio. Igualmente, el uso de las leyendas, viene a desarrollar las habilidades sociales y de autoestima cuando permite la socialización activa con los mismos compañeros en el salón de clase. Es una interacción constante que se desarrolla con la promoción de actividades paralelas a la narración de la leyenda. Esto último no solo se da entre los compañeros; existe una interrelación entre el individuo y la comunidad, su medio natural en el sentido de concientización en la protección del medio ambiente y del legado cultural e histórico, promoviendo la reflexión y el pensamiento lógico sobre el mundo natural, social y cultural económico.

Objetivos en el uso de leyendas en la mediación pedagógica

- Establecer e identificar elementos culturales a valorar y preservar.

- Identificar de manera natural, aspectos claves y referentes de identidad cultural propias al país.

- Destacar entornos físicos y sociales que aportan a la identidad cultural

- Reconocer el pasado, con sus elementos simbólicos o referentes que ayudan a construir el futuro.

- Reconocer características propias de los pueblos y su creatividad.

- Destacar las competencias heredadas que se continúan desarrollando.

- Proponer dimensiones de corte social y natural necesarias para que perduren e inspiren dentro de sus comunidades,

- Concientizar y promover sentimientos de continuidad y de nexo con las generaciones venideras.

Las leyendas costarricenses 
De acuerdo con el recopilador Elías Zeledón (2004),en su libro "Las Leyendas Costarricenses" las leyendas ticas versan sobre almas en pena, magia o cultura indígena, y éstas giran sobre un eje central que es la religión, característica preponderante en la sociedad costarricense. Es así como el autor Zeledón recopila las leyendas bajo tres grandes secciones como leyendas de la tierra en las que se destacan la leyenda de Iztarú, El Irazú, y la Leyenda del Zurquí, entre otras. Otra sección corresponde a la parte de religión con leyendas como La Yeguita, El Cristo Negro de Esquipulas, y las leyendas de la Aparición de la Virgen de los Ángeles. Por último, está la sección de leyendas de la Magia con leyendas como "El Padre sin Cabeza", "La Llorona", "El Cadejos" y "La Segua", entre muchas otras. Precisamente, las más populares son las leyendas del "Cadejos", "La Segua" y la "Llorona", esta última popular también presente en otros países como México.

En la provincia de Guanacaste, es muy popular la leyenda de "La Mona". Como docentes de Inglés a nivel superior en la UNA y UCR es que encontramos en esta leyenda, muchos elementos por rescatar de la cultura guanacasteca a la vez que se enseña el idioma Inglés, de ahí nuestro interés de tomarla como recurso para desarrollarla en el salón de clase y con ello, sacar provecho de los beneficios en el uso de las leyendas como material didáctico.

Actividades de Aprendizaje

Actividad 1: "Leyendas Costarricenses: La Mona"

Objetivos:

-Analizar la leyenda de la mona en forma creativa y dinámica desde una perspectiva cultural, social y gramatical.

-Desarrollar las habilidades comunicativas por medio del discurso oral y escrito.

-Ampliar, enriquecer y fortalecer conocimientos sobre las costumbres, valores y creencias del costarricense, en este caso, de Guanacaste, mediante la leyenda.

Material

La leyenda de "La Mona"

Procedimientos:

1. El docente inicia la lección con una introducción a las leyendas costarricenses preguntando que han escuchado sobre leyenda de "La Mona".

2. El docente motiva a los estudiantes a destacar similitudes en sus relatos sobre esta leyenda. 
3. Luego, la docente facilita la leyenda de la Mona y motiva a los estudiantes a parafrasear los párrafos en inglés.

4. Una vez que los estudiantes han leído la leyenda, el docente clarifica el vocabulario difícil y equivalencias en el idioma meta para facilitar la comprensión del texto.

5. Seguidamente, se establece una discusión /debate en relación al tema y contenido cultural de la leyenda de "La Mona". Se discute acerca de las costumbres, tradiciones y valores de la Costa Rica de antaño reflejadas en la leyenda.

6. En grupos, los estudiantes trabajan el vocabulario difícil así como regionalismo de la época y para luego realizar un resumen de la leyenda en Inglés.

7. Como actividad final los estudiantes sintetizan la enseñanza /moraleja que deja la leyenda de "La Mona" y se entrevistan sobre sus percepciones generales.

8. Como conclusión final se pueden realizar comparaciones sobre el folklore entre ambas el culturas: la costarricense y las de habla inglesa.

Hoja de trabajo: La leyenda de "La Mona"

A continuación se presenta a manera de síntesis la leyenda de "La Mona".

\section{La leyenda de "La Mona"}

"Se dice que en las oscuras noches, cuando se acerca la medianoche y Guanacaste duerme bajo la luna llena...una desdichada mujer transformada en una horripilante criatura asusta a los transeúntes que deambulan por los solitarios caminos. A veces la mona se atreve a llegar hasta los barrios céntricos de los pueblos, correteando sobre los techos de las casas, arañando el zinc con sus garras. Se cuenta que muchos años atrás, quizás desde tiempos coloniales, una guapa mujer fue trasformada en mona por una bruja. Mucha gente dice que la espantosa conversión ocurrió debido a la envidia que la bruja tenía hacia la extrema belleza de esa mujer... Otros afirman que fue transformada en tan horripilante criatura debido a un castigo que le propicio la hechicera por contar falacias sobre ella.

Acerca de "La Mona", se puede decir que es una criatura, efectivamente, con la cara con aspecto de simio, de baja estatura, con su cuerpo cubierto de pelos, con ojos rojos y penetrantes, además de tener un grito escalofriantemente desesperante y aterrador. Normalmente es enviada por algún 
brujo o bruja a atacar a una persona en especial... Aunque muchas veces "La Mona" simplemente deambula por ahí asustando y molestando al primer desdichado que se le aparezca en frente, agobiándolo con sus gritos y rasguños, con su mirada y su presencia...Con ese sentimiento infernal que la rodea.

Cuenta uno de sus víctimas, un humilde hombre guanacasteco, que tuvo a "La Mona" como su mujer sin percatarse de ello. Empezó a notar algo extraño cuando, la que creía su mujer, se desaparecía en la madrugada de la cama que compartían para convertirse en "La Mona". Entonces, un día se despertó en la madrugada para seguir a su mujer. Su sorpresa fue ver que la mujer dejaba su cama y se desaparecía en la oscuridad, dejando a su paso su piel para convertirse en "La Mona". Antes del amanecer, "La Mona" regresaba y se acostaba en su cama con su marido pero ya convertida, de nuevo, en la mujer hermosa que él creyó conocer. Al ver esto, el hombre se contactó con un amigo quien le indicaría que debía hacer para ahuyentar la maligna transformación de su mujer. Así pues, un noche, decidió seguir a la mujer y en su recorrido, observó como su mujer se despojaba de su piel para dejarla en una bandeja y así salir corriendo convertida en mona y perderse en la oscuridad del bosque. Siguiendo las indicaciones de su amigo, procedió a echarle sal bendita al despojo de piel dejado por "La Mona". La sal bendita impediría que "La Mona" pudiera colocarse de nuevo la piel de mujer y así no podría regresar al lecho que compartía con el desafortunado hombre pues se descubriría su verdadera identidad. Y así fue, cerca de las tres de la madrugada el hombre oyó una bulla, era "La Mona" que intentaba pegarse la piel de mujer. Después de muchos intentos de colocarse la piel, "La Mona" se dio por vencida y se regresó al oscuro bosque. El hombre vio como, finalmente, "La Mona" se desaparecía de su vida. Nunca más la volvió a ver. Pero, amantes de la noche, tengan cuidado, "La Mona" anda por ahí, merodeando y agobiando con sus gritos y rasguños, con su mirada y presencia, buscando, acechando a una próxima víctima que caiga en sus engaños.

Adaptado de Leyendas de Gente a Gente (2010) y Video "La leyenda de La Mona" Montero, P., Torres, C., y Villanueva, L. (2010) 


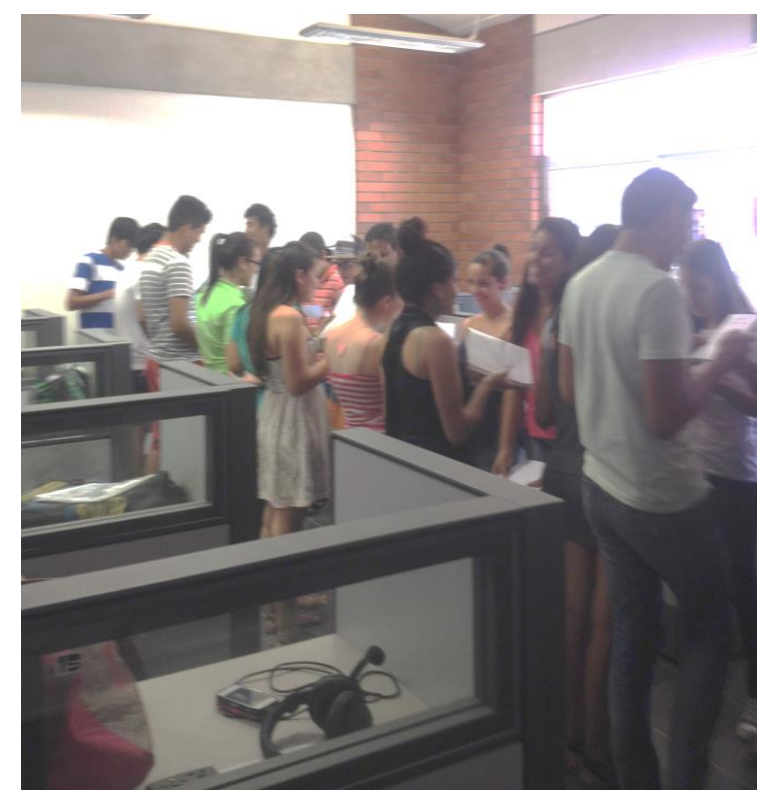

Figura 1: Contando mi versión de la leyenda

Actividad 2: "Contando mi versión de la leyenda" Objetivo

Los estudiantes serán capaces de:

-Discutir y evaluar el problema central en la leyenda de la Mona.

-Desarrollar habilidades de escucha, de producción oral y expresión escrita.

Material

Versiones impresas de experiencias, revistas, periódicos, papel de construcción.

Procedimientos:

1. El docente socializa dos experiencias sobre encuentros con "La Mona" extraídos de un blog en Internet. Al leerlos los estudiantes piensan sobre similitudes en las versiones.

2. El docente motiva a los estudiantes a contar su versión de la leyenda de la Mona y los aspectos de la misma que más les impacto esto lo harán interactuando frente a frente en dos líneas. Una línea A y otra línea de estudiantes B. La línea de estudiantes A, expresan sus perspectivas mientras que la línea $\mathrm{B}$, escuchan y realizan preguntas espontaneas según surjan dudas en el relato de los compañeros(conversación en inglés).

3. El docente entrega la leyenda de "La Mona", la cual se lee y analiza en grupos, los estudiantes guían su discusión con una guía de ideas proporcionada por el profesor.

4. Los estudiantes crearán un collage utilizando frases, expresiones, ideas, datos y dibujos en relación al contenido de la leyenda. 
5. En grupos los estudiantes intercambian su collage para determinar los aspectos y la problemática. Se motiva la discusión grupal interactiva e equitativa.

6. En plenaria, el profesor(a) y los estudiantes abren una discusión en torno a los valores y aspectos culturales destacados en la leyenda.

Hoja de trabajo: Relatos sobre apariciones de la Mona

Relato 1

En mi expueblo en Upala y alrededores siempre sale La Mona, que es una bruja que según los relatos de vecinos se transforma en mona. Esta mujer no se ha podido ver bien, las fotos que se han visto son poco visibles pero si la escuchas de lejos está de cerca y si la escuchas de cerca está de lejos. Yo la escuché, hace un grito espantoso y casi siempre lo que hace es solo asustar. Los abuelos dicen que para alejarla hay que rezar las doce palabras o decirle sin miedo que se le echara sal así saldrá espantada y si en realidad se le echa sal (bendita) se muere porque al parecer deja la piel en su casa y cuando regresa no se la puede poner. Le dicen la mona porque brinca en los árboles como un mono pero es una mujer. Asusta por diferentes razones: porque le cae mal alguien, si es una vecina con la que hay conflictos o si es la amante de tu esposo te llega asustar exclusivamente a vos a tu casa. También asusta al que está a altas horas de la noche en ciertas partes. A mí me contaron varias historias incluso anduvo siguiendo a mi novio después de una visita a la casa, y a mi hermano después de visitar a la novia. Un amigo me contó que ellos venían de una fiesta en motocicleta (él y su hermana) y que les sale esa bicha como a las 2 de la mañana dice que apretó todo el gas y que aún así corría detrás de ellos así hasta que se cansó. Tomado de: Foro de Costa Rica.

Relato 2.

Cuando era niña en Puntarenas, estaba yo en un potrero con un amigo bajando mangos de un árbol. Al irnos hacia la casa vimos que detrás nuestro venia corriendo la mona. Venia tan rápido que cuando nos dimos cuenta nos estaba pisando los talones, nosotros seguimos corriendo porque teníamos miedo de lo que nos podría hacer, teníamos miedo de que nos hiriera, por lo que seguimos corriendo. Muy tarde me di cuenta que mi amigo se había quedado atrás, en el suelo pero preferí no volver atrás por miedo, los ruidos de este monstruo eran horripilantes que me hicieron perder todas las fuerzas, yo solo corría. Nunca me volvió a hablar mi amigo, nunca supe que le sucedió.

Tomado de: Aporte en foro por Gabriela Morales. 


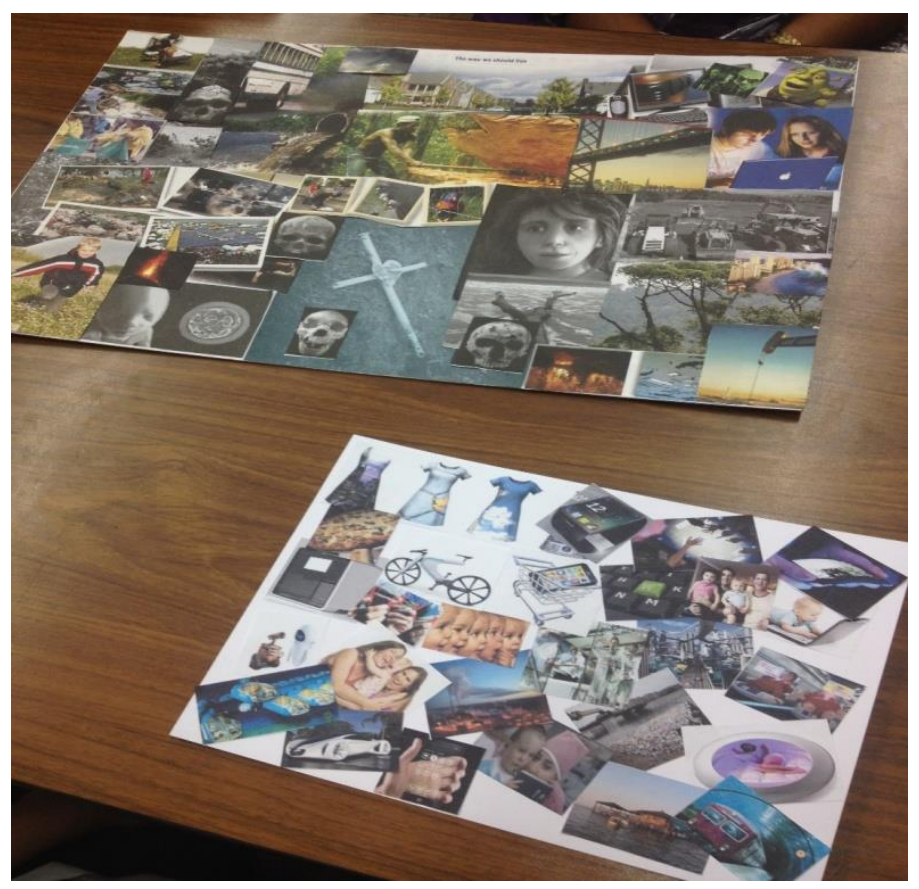

Figura 2: Representando la leyenda

Actividad 3: "Representando la leyenda"

Objetivo

Los estudiantes serán capaces de:

-Analizar y representar la leyenda de "La Mona".

-Desarrollar habilidades de escucha, de producción oral y expresión escrita.

- Desarrollar su creatividad e iniciativa, capacidad de organización y trabajo en equipo.

- Identificar elementos propios de su cultura en la leyenda de "La Mona", analizando las causas y efectos de los hechos relatados.

1. Los estudiantes ven el video de "La Mona". Se discute las primeras impresiones del mismo para evaluar la comprensión del relato.

2. Como complemento, la profesora les facilita la leyenda por escrito y se establecen interrogantes en torno al argumento, describiendo los personajes de la historia y explicando como son qué sienten y porqué reaccionan así.

3. Los estudiantes en grupos preparan su propia versión de "La Mona", pudiendo establecer nuevos conflictos por resolver, variar el desenlace y añadir personajes en esta leyenda. Para ello, escribirán un guion con los diálogos que serán dramatizados. 
4. En esta representación o dramatización, los estudiantes pueden utilizar los recursos tecnológicos para realizar foto y/o video corto de lo representado. Se realiza en el idioma inglés.

5. Como actividad final posterior a la presentación de las presentaciones de las diferentes versiones de "La Mona", la profesora establece una serie de preguntas en torno al contenido de la historia y motiva a los estudiantes a expresar las razones que los llevaron a montar las versiones de "La Mona" expuestas, los diferentes argumentos en cada una, así como lo que sintieron al proyectarse como los personajes en la leyenda.

6. Los estudiantes escriben su experiencia relacionando los problemas de los personajes con los de la vida real.

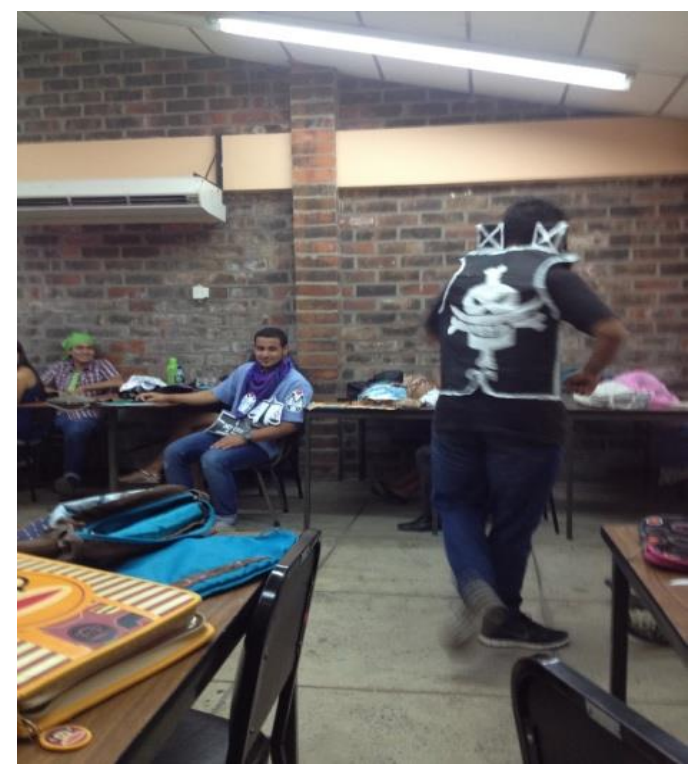

Figura 3: Percepciones generales de los estudiantes

Percepciones generales de los estudiantes

Estas actividades han sido utilizadas con estudiantes de la Universidad Nacional y de la Universidad de Costa Rica, campus Liberia y sede Guanacaste mediados desde la enseñanza del idioma Inglés en cursos de Inglés integrado I y II que se ofertan en ambas universidades. Mediante la observación participativa en diferentes momentos de las clases se evidenció una mayor cohesión grupal y mucho más disfrute al realizar las diferentes actividades de aprendizaje. Los estudiantes más tímidos se sintieron empoderados a participar pues tenían versiones contadas por sus abuelos y familiares por compartir con sus compañeros de clase. De igual manera, los estudiantes se sorprendieron por las diferentes versiones de la leyenda encontradas en diversas zonas del país. 
En la discusión abierta los estudiantes se mostraron interesados y atentos a las participaciones de todos. Se proyectó una interacción más amena y amigable, se percibió a los estudiantes alertas y comunicativos. En ambos cursos los estudiantes destacan los siguientes aspectos:

- Valoraron como novedad en el aula universitaria el uso del recurso de la leyenda para reforzar el aprendizaje del Inglés y otros valores culturales que por lo general no son tan explícitos en la enseñanza en general.

- Destacaron la innovación frecuente, es decir, que no se limite a los ejercicios tradicionales para enseñar cualquier materia.

- Ambos grupos subrayaron lo beneficioso que resulta desarrollar actividades que permitan promover la creatividad, el análisis y el pensamiento crítico. Esto se logró en momentos claves de las actividades como en la representación o dramatización,

- De igual manera, apreciaron el hecho de analizar y relacionar el relato de "La Mona" su tema central, con los problemas de la vida actual y cotidiana.

- El desarrollo de la creatividad y el análisis que fue promovido, principalmente, con la elaboración de un collage con frases, expresiones y dibujos sobre el contenido de la leyenda.

- A nivel específico sobre la enseñanza del Inglés los estudiantes destacaron el uso y el aprendizaje de nuevo vocabulario así como la espontaneidad y familiaridad en la interacción generada por un tema poco destacado pero atractivo.

- Fue relevante para los estudiantes el hecho de que les cautivó su atención los relatos de la "La Mona” en sí mismo. El uso del misterio como género los mantuvo atentos en todas las actividades didácticas concernientes a "La Mona".

- Se logró integrar a todos en beneficio de sus particularidades individuales en el trabajo cooperativo promoviendo un aprendizaje inclusivo a la vez que se reforzaron sus estilos de aprendizaje.

\section{Conclusiones}

La identidad supone un reconocimiento y apropiación de la memoria histórica, del pasado. Un pasado que puede ser reconstruido o reinventado, pero que es conocido y apropiado por todos. El valorar, restaurar, proteger el patrimonio cultural es un indicador claro de la recuperación, reinvención y apropiación de una identidad cultural que debe ser responsabilidad de todos los 
individuos de una sociedad, producto de un sistema educativo comprometido con el arraigo cultural de sus ciudadanos.

El uso de leyendas como material didáctico promueve un aprendizaje integral que afianza el conocimiento cultural como parte de lo que somos y representamos en nuestro núcleo social, a la vez que permite que este proceso de enseñanza - aprendizaje sea, además de rico en contenido, signifique algo en el estudiante y que en este camino, se sienta atraído, entretenido, y sacudido por la experiencia al tocar sus sentimientos y emociones. Las leyendas en el aula, y en este caso, la de la leyenda guanacasteca de "La Mona", es una oportunidad para que el educando interactúe con sus pares y con el profesor o tutor y se trabaje en equipo. Leyendas como la citada generan momentos de aprendizaje para contextualizar contenidos. Es una herramienta con la cual se impulsa la producción oral, la producción escrita, la imaginación, la creatividad, el uso de la criticidad, la reflexión conjunta y solución de problemas.

Las actividades didácticas destacadas en este artículo como la lectura previa, la identificación del vocabulario difícil y el estudio gramatical, debates, preguntas generadoras, la producción oral y escrita, resúmenes y representaciones con variantes creativas de la leyenda misma, por mencionar algunas de las acciones sugeridas, desarrollan el pensamiento crítico y guían hacia un aprendizaje global. Integrado e inclusivo. Los estudiantes aprenden por descubrimiento, interrelacionándose con el contenido y los problemas acontecidos y que narrados de manera misteriosa e inquietante, incentivan finalmente, un proceso académico efectivo y exitoso. A nivel cultural y social, los estudiantes identifican los elementos que relevan aspectos de la cultura costarricense tales como: costumbres, tradiciones y valores religiosos inmersos en la leyenda. Los centros de enseñanza deben ser formadores integrales. "La escuela es una instancia de mediación cultural entre los significados, sentimientos y conductas de la comunidad social y el desarrollo particular de las nuevas generaciones" (Pérez Gómez, 2000).

\section{Referencias:}

Bock, Susan. (1989). Developing materials for the study of literature: Creative classroom activities. English Teaching Forum, 8, 73-82.

Díaz, M. (agosto-diciembre, 2009) Reflexiones: Tiempos líquidos sobre el Patrimonio Cultural y sus Valores. Revista digital Estudios Históricos, (2) ISSN: 1688-5317. Recuperado de: http://www.estudioshistoricos.org/edicion_2/maria_diaz.pdf 
De la Torre, S. (2005). Sentipensar: Fundamentos y Estrategias para Reencantar la educación. Málaga: Ediciones Aljibe.

Ennis, R. (2011). The Nature of Critical Thinking: An Outline of Critical Thinking Dispositions and Abilities. Robert H. Ennis' Academic Web Site. Recuperado de:http://faculty.education.illinois.edu/rhennis/documents/TheNatureofCriticalThinking_5 1711_000.pdf

Geertz, C (1989) "El impacto del concepto de cultura en el concepto del hombre en la interpretación de las culturas. Gedisa, Barcelona Recuperado de http://inicia.es/de/cgarciam/geertz01.htm

Gonzales, I. (2006) Conservación de Bienes Culturales: teoría, historia, principios y normas. 5 ed. Madrid: Catedra

González (2015) Patrimonio Cultural: conceptos, debates y problemas. Resumen Recuperado de http://www.casadellibro.com/libro-patrimonio-cultural-conceptos-debates-yproblemas/9788437634173/2546437

Leyendas de Gente a Gente. (2009) Leyenda La Mona. Recuperado de http://leyendasdegenteagente.blogspot.com/2009/06/se-dice-que-en-las-oscurasnoches.html

Montero, P., Torres, C., y Villanueva, L. (2010) Leyenda de la Mona. San José: Centro de Cine. Video You Tube. Recuperado de: https://youtu.be/N_2UXyYhzHg

Morales, G. ( 3 de junio del 2009). Re: La Mona [Comentario de un foro en línea]. Recuperado de http://leyendasdegenteagente.blogspot.com/2009/06/se-dice-que-en-las-oscurasnoches.html

Paul, R. (2001). Características de un pensador crítico. En Muñoz Hueso \& J. Beltrán Llera, Fomento del pensamiento crítico mediante la intervención en una unidad didáctica sobre la técnica de detección de información sesgada en los alumnos de Enseñanza Secundaria Obligatoria en Ciencias Sociales. España: Universidad Complutense de Madrid. Departamento de Psicología Evolutiva y de la Educación. Recuperado de http://www.psicologiaonline.com/ciopa2001/actividades/54

Pérez, A. (2004) La cultura escolar en la sociedad Neoliberal. Madrid: Editorial Morata. Resumen Recuperado de http:/www.uma.es/investigadores/grupos/grupo5123/comp/aiperez.htm

Reyes, M. (2011). Narrar y comentar mitos y leyendas en el aula para el manejo de miedos y temores del niño. México: Universidad Pedagógica Nacional. Recuperado de: http://200.23.113.59/pdf/28173.pdf

Urd. (21 de setiembre del 2010) Re: La mona atrapada en mi pueblo [Comentario de un foro en línea]. Recuperado de http://www.forodecostarica.com/filosofia-religion-ficcion-yciencia/48889-la-mona-atrapada-en-mi-pueblo.html 
InterSedes, $\mathbf{N}^{\circ}$ 43. Vol XXI (2020). ISSN 2215-2458

UNESCO (16 de setiembre del 2015). Re: Qué es el Patrimonio Cultural Inmaterial. Recuperado de: http://www.unesco.org/culture/ich/index.php?lg=es\&pg=00002

Zeledón, E. (2004). Leyendas Costarricenses. Heredia: Editorial Universidad Nacional EUNA 